\title{
Towards a Green Economy in Europe: Does Renewable Energy Production Has Asymmetric Effects On Unemployment?
}

\author{
Sameen Naqvi \\ Wuhan University \\ Jinchao Wang \\ Wuhan University \\ Rizwan Ali ( $\nabla$ rizwan.ali@uskt.edu.pk) \\ University of Sialkot
}

\section{Research Article}

Keywords: Renewable energy production, Unemployment, Europe

Posted Date: September 20th, 2021

DOI: https://doi.org/10.21203/rs.3.rs-876311/v1

License: (c) (i) This work is licensed under a Creative Commons Attribution 4.0 International License.

Read Full License

Version of Record: A version of this preprint was published at Environmental Science and Pollution Research on October 26th, 2021. See the published version at https://doi.org/10.1007/s11356-02117093-2. 


\title{
Towards a green economy in Europe: does renewable energy production has asymmetric effects on unemployment?
}

\section{Sameen Naqvi}

Economics and Management School, Wuhan University, China. naqvisameen86@yahoo.com

\author{
Jinchao Wang \\ Economics and Management School, Wuhan University, China. jcwang@whu.edu.cn
}

\section{Rizwan Ali**}

**Corresponding author

Commerce department, University of Sialkot, Pakistan. $\underline{\text { rizwan.ali@uskt.edu.pk }}$

\begin{abstract}
Renewable energy production is necessary for digital society; it is also beneficial for labour market and sustainable development. This paper examines the impact of renewable energy production on unemployment rate by employing panel NARDL-PMG and robust asymmetric quantile regression for European countries from 1991 to 2019. The results reveal that renewable energy production is significantly reduced unemployment in European countries in long run. The renewable energy production effect is found significant in the asymmetric model, specifically, in European countries; a positive change in renewable energy production has a negative significant impact on unemployment, and a negative change in renewable energy production has a positive significant impact on unemployment in long-run. The GDP, investment, and technology innovation process is found to be triggered in labour market by reducing the unemployment rate in the long-run. In addition, the asymmetric effects of renewable energy production on unemployment growth are robust in the different quantile regression. The findings suggest some insightful policy implications for government officials and policymakers.
\end{abstract}

Keywords: Renewable energy production. Unemployment. Europe

\section{Introduction}

Over the past few decades, climate change has become a primary concern for policymakers worldwide. Climate change and its related problems, such as global warming, rising sea levels, floods, droughts, etc., have jeopardized the survival of mankind on earth (Usman et al., 2020). One of the primary causes of global climate change is the emissions of greenhouse gases (GHGs) due to man-induced economic and social activities. Among the GHGs, carbon dioxide ( $\mathrm{CO} 2)$ has the largest share of $76 \%$, followed by methane $(\mathrm{CH} 4) 16 \%$, nitrous oxide $(\mathrm{N} 2 \mathrm{O}) 6 \%$, and others $2 \%$. The excessive infusion of $\mathrm{CO} 2$ emissions into the atmosphere is considered a crucial proxy of environmental degradation. Many empirics have tried to find the factors to curb $\mathrm{CO} 2$ emissions without hampering economic and social activities. 
The talks at the international level are getting serious about the efficacy of renewable energy in mitigating $\mathrm{CO} 2$ emissions after the publication of the fourth assessment report (AR4) by the international panel on climate change (IPCC) in 2007. The European Commission on climate change suggests that Europe can play a leading role in the worldwide efforts to curb GHGs emissions and set a target of reducing emissions by $30 \%$ with the help of other nations. Although the benefits of renewable energy in terms of energy security, resource preservations, climate protection, and import independence are undisputed; however, actual economic costs of renewable energy projects are still a point of controversy because of the high upfront costs of such projects.

Given the importance of renewable energy and its related economic benefits, many studies with different geographical focuses have discussed the relationship between renewable energy and economic growth without assessing the value-added. Breitschopf et al. (2016) covered the literature with regards to the impacts of renewable energy on employment opportunities. They extensively reviewed two different methods of estimating the relationship. One highlighted the positive effects of renewable energy on unemployment, while another highlighted the adverse impacts of renewable energy. They offered six different techniques and determined that the input-output modelling method is most appropriate for national investigation because of its worldwide approach.

As already discussed that the renewable energy has a crucial role in improving environmental quality (Pachauri et al, 2014). The placement of renewable energy projects is beneficial for all stakeholders. It presents a win-win situation in terms of society's environment and economic well-being by curbing CO2 emissions and increasing employment opportunities in different economic segments via direct and indirect channels. According to International Renewable Energy Agency (2011), renewable energy can create job opportunities in almost every economic sector. Most of the studies in the literature also supported this notion (Meyer and Sommer, 2014).

The deployment of renewable energy projects saw a massive surge after 2012, and more than 11 million people worldwide are serving in the renewable energy sector (Meyer and Sommer, 2014). The swiftly growing development of renewable energy projects and technologies and the increasing numbers of employment opportunities make it vital to explore the occupation effect of renewable electricity (Apergis \& Salim, 2015). In the existing literature, many studies have focused on the employment effects of renewable energy concerning different locations; however, most of the studies ignored the employment opportunities created by nuclear and non-renewable energy sources (Cameron and Zwaan, 2015 and Azretbergenova et al. 2021). They extensively reviewed the literature on the employment effects of renewable energy and suggested that the size of net employment effects differs significantly because of variations in geography, technologies, econometric methodologies, and data collection. They also highlighted that there is no consensus vis-à-vis the long-run sustainability in employment effects of the renewable energy sector (Rivers 2013; Mbarek et al. 2018; Çelik, 2021).

The share of renewable energy in total energy mixes of different countries is on the rise, particularly in the developed economies such as Europe, where $34 \%$ of the total electricity demand is fulfilled via renewable energy sources in 2019. On the other side, the share of renewable energy sources soared to $19.7 \%$ of total energy in 2019, while this number was just 9.6\% in 2004 (Eurostat, 2019). Though the benefits of renewable energy are many, most notables are improved environmental quality and increased energy security. Another significant benefit of renewable energy is job creation which is also noted by the various studies; however, this 
claim is still debatable. Although multiple studies have supported the argument that renewable energy projects benefit the economy by creating job opportunities (UNEP, 2011; Moreno \& Lopez, 2008; Blanco and Rodrigues, 2009), but these studies have relied on very positive or simple expectations, thus provided such results. In some instances, a rational approach is adopted by considering reasonable suppositions, but discriminatory findings can drive a wrong image of job creation. Previous literature confirmed that large-scale and massive investments in renewable energy projects could positively affect employment opportunities at a much greater pace than the employment effects of small renewable projects with low-level investments (Böhringer et al. 2013; Yi, 2013).

Against this backdrop, in this analysis, our primary focus is to analyze the impact of renewable energy on employment opportunities in European economies. European countries are rapidly adopting renewable energy technologies, and it has become a vital provider of electricity and energy inside Europe. Hence, these economies have become the ideal countries to study the impact of renewable energy projects on employment opportunities. Moreover, we also want to observe whether the employment growth responds symmetrically or asymmetrically to the changes in renewable energy production. To that end, we have applied non-linear PanelNARDL-PMG, which provides us the opportunity to break down the renewable energy production into their positive and negative shocks; thus, separately calculate their impact on employment growth in Europe. The asymmetric analysis is closer to reality because most of the macroeconomic variables behave nonlinearly due to their vulnerability to external shocks. The non-linear analysis assumes that a positive and negative change may move in the same direction with different magnitudes. Furthermore, to strengthen our results, we will also apply the quantile regression model.

This study is a blend of various sections, and their organizations are as follows. In section two, we present data and methods. Then, we offer results in section three. We have provided the conclusion in the fourth section.

\section{Model and methods}

A majority of the studies in the literature identify renewable energy production as one of the key factors of employment. Hillebrand et al. (2006) revealed that renewable energy production has importance in their formulation of the labor market. Therefore, we follow Arvanitopoulos and Agnolucci (2020) and adopt the following long-run model:

$$
\text { Unemp }_{\text {it }}=\omega_{0}+\varphi_{1} \text { REP }_{\text {it }}+\varphi_{2} \mathrm{GDP}_{\mathrm{it}}+\varphi_{3} \text { Investment }_{\mathrm{it}}+\varphi_{4} \text { Technology }_{\mathrm{it}}+\varepsilon_{\mathrm{t}}
$$

Where Unemp it $_{\text {is }}$ employment rate, $\mathrm{REP}_{\mathrm{it}}$ is renewable energy production, GDP it is GDP per capita, Investment $_{i t}$ is investment share, and Technolghy $y_{i t}$ is technology innovation. Since data sampling nations is Europe, we express the " $i$ " and time period " $t$ ". It is normally assumed that an increase in renewable energy production encourages the employment rate. Thus, we expect estimates of $\varphi_{1}$ to be negative. The next phase involves re-writing equation (1) in an error-correction modeling format so that we can also measure the shortrun impacts of exogenous variables. Such model is outlined by (2) as follows: 
$\Delta$ Unemp $_{\mathrm{t}}=\omega_{0}+\sum_{\mathrm{k}=1}^{\mathrm{n}} \beta_{1 \mathrm{k}} \Delta$ Unemp $_{2, \mathrm{t}-\mathrm{k}}+\sum_{\mathrm{k}=0}^{\mathrm{n}} \beta_{2 \mathrm{k}} \Delta \mathrm{REP}_{\mathrm{t}-\mathrm{k}}+\sum_{\mathrm{k}=0}^{\mathrm{n}} \beta_{3 \mathrm{k}} \Delta \mathrm{GDP}_{\mathrm{t}-\mathrm{k}}+$ $\sum_{\mathrm{k}=1}^{\mathrm{n}} \beta_{4 \mathrm{k}} \Delta$ Investment $_{\mathrm{t}-\mathrm{k}}+\sum_{\mathrm{k}=0}^{\mathrm{n}} \beta_{5 \mathrm{k}} \Delta$ Technology $_{\mathrm{t}-\mathrm{k}}+\omega_{1} \mathrm{Unemp}_{\mathrm{it}-1}+\omega_{2} \mathrm{REP}_{\mathrm{t}-1}+\omega_{3} \mathrm{GDP}_{\mathrm{t}-1}+$ $\omega_{4}$ Investment $+\omega_{5}$ Technology $y_{t-1}+\varepsilon_{t}$

Specifications (2) is due to Pesaran et al. (2001) where coefficients are attached to "first-differenced" variables and the long-run coefficients by the estimates of $\omega 2-\omega 5$ normalized on $\omega 1$. However, for the consistency and validity of long-run estimates, we must establish cointegration. Two famous tests are recommended in the literature (Pesaran et al. 2001). The F test to establish the joint significance of lagged level variables and the ttest or ECM to establish the significance of $\omega_{1}$ in equation (2). The central assumption in the error-correction model (3) is that the impact of renewable energy production on the unemployment rate is symmetric. Shin et al. (2014) modify such a type of econometric model so that we can easily judge the possibility of asymmetric effects of renewable energy production on the unemployment rate.

$$
\begin{aligned}
\operatorname{REP}^{+} & =\sum_{n=1}^{t} \Delta \operatorname{REP}^{+}{ }_{t}=\sum_{n=1}^{t} \max \left(\operatorname{REP}^{+}{ }_{t}, 0\right) \\
\operatorname{REP}^{-} & =\sum_{n=1}^{t} \Delta \operatorname{REP}^{-}{ }_{t}=\sum_{n=1}^{t} \min \left(\Delta \operatorname{REP}^{-}{ }_{t}, 0\right)
\end{aligned}
$$

Thus, the concept of the partial sum is employed to create two new time series as, $\operatorname{REP}^{+}{ }_{\mathrm{t}}$ and $\mathrm{REP}^{-}{ }_{\mathrm{t}}$. A positive change in renewable energy production and reflects only an increase in renewable energy production. By the same token, $\mathrm{REP}^{-}$is the partial sum of negative change and reflects on the decreased renewable energy production. In the next step, we move back to (2) and replace $\mathrm{REP}_{\mathrm{it}}$ with the partial sum of two new variables to arrive at:

$$
\begin{aligned}
& \Delta \mathrm{Unemp}_{2, \mathrm{t}}=\omega_{0}+\sum_{\mathrm{k}=1}^{\mathrm{n}} \delta_{1 \mathrm{k}} \Delta \mathrm{Unemp}_{2, \mathrm{t}-\mathrm{k}}+\sum_{\mathrm{k}=0}^{\mathrm{n}} \delta_{2 \mathrm{k}} \Delta \mathrm{REP}_{\mathrm{t}-\mathrm{k}}^{+}+\sum_{\mathrm{k}=0}^{\mathrm{n}} \delta_{3 \mathrm{k}} \Delta \mathrm{REP}_{\mathrm{t}-\mathrm{k}}^{-}+ \\
& \sum_{\mathrm{k}=0}^{\mathrm{n}} \beta_{4 \mathrm{k}} \mathrm{GDP}_{\mathrm{t}-\mathrm{k}}+\sum_{\mathrm{k}=0}^{\mathrm{n}} \beta_{5 \mathrm{k}} \text { Investment }_{\mathrm{t}-\mathrm{k}}+\sum_{\mathrm{k}=0}^{\mathrm{n}} \beta_{6 \mathrm{k}} \text { Technology }_{\mathrm{t}-\mathrm{k}}+\omega_{1} \text { Unemp }_{\mathrm{t}-1}+\omega_{2} \mathrm{REP}_{\mathrm{t}-1}^{+}
\end{aligned}
$$$$
\omega_{3} \text { REP }^{-}{ }_{t-1}++\omega_{4} \mathrm{GDP}_{\mathrm{t}-1}+\omega_{5} \text { Investment }_{\mathrm{t}-1}+\omega_{6} \text { Technolghy }_{\mathrm{t}-1}+\varepsilon_{\mathrm{t}}
$$

Since assembling the two new partial sum variables of the renewable energy production, models like equation (4) is referred to as asymmetric ARDL model whereas, that like equation (2) is called asymmetric ARDL model. Shin et al. (2014) employed a similar estimation approach and the same diagnostic for both linear and nonlinear models. Once equation (5) is estimated, a few nonlinearity assumptions could be tested. First, short-run asymmetry can be established if $\triangle \mathrm{REP}^{+}$and $\triangle \mathrm{REP}^{-}$take a different lag order, i.e., if $\delta_{2 \mathrm{k}} \neq \delta_{3 \mathrm{k}}$. Second, short-run asymmetric impacts of renewable energy production will be established by using Wald test, if at any given lag order $\mathrm{k}$, the estimate of $\delta_{2 \mathrm{k}}$ attached to $\Delta \mathrm{REP}^{+}{ }_{\mathrm{t}-\mathrm{k}}$ is different than the estimate of $\delta_{3 \mathrm{k}}$ attached to $\triangle \mathrm{REP}^{-}{ }_{\mathrm{t}-\mathrm{k}}$. Lastly, the long-run asymmetric impacts between the positive and negative changes are established if, once again, we can reject the null hypothesis of the Wald test $\left(\frac{\omega_{2}}{-\omega_{1}}=\frac{\omega_{3}}{-\omega_{1}}\right)$.

Some scholars also apply the quantile technique on the panel data and give large attention in theory and application. Quantile regression has become a workhorse in recent years and has been widely used in energy and environmental empirical research. Koenker \& Bassett (1978) offers an insight into the relationship of the response variable distribution on the covariates in the various quantiles in Quantile regression. It is noted that fat 
tails or distinct peaks often exist in the data, while the panel data model is mostly estimated based on conditional mean regression. To alleviate this difficulty, we utilize panel quantile regression to estimate our non-linear econometric model. The quantile regression provides more robust estimation results for panel data (Koenker and Bassett, 1978). This method allows exploring a range of conditional quantiles by capturing asymmetric effects. Koenker (2004) proposes a different quantile regression model based on the fixed-effects panel data, where the different term is added to the objective function to decrease the individual impacts and maintain the asymptotic normality of the estimator.

The panel asymmetric quantile regression also deals with the outliers and offers robust outcomes.

162

163

164

165

166

167

168

169

170

171

172

173

174

175

176

177 Panel quantile regression delivers a separate influence of concern variables on unemployment due to varied quantiles. Panel quantile regression also explores unobserved heterogeneity for each cross-section and measures various parameters in different quantiles.

\section{Data}

The study aims to investigate the impact of renewable energy production on employment growth in European economies (Germany, Italy, France, Sweden, Spain, Norway, UK, Finland, Austria, Poland) for the period 1991 to 2019. Unemployment as a percentage of the total labor force is used to measure unemployment growth. Renewable energy production is measured as renewables and others in quad Btu. GDP, investment, and Patent are control variables in this study. GDP is measured as GDP per capita at constant 2010 US\$. Gross fixed capital formation as a percentage of GDP is used as a proxy variable for investment. A patent variable is used as a proxy variable for technological innovation which is measured as patent applications in a number of total residents and non-residents. Data on all variables are extracted from the World Bank.

Table 1: Variables and definitions

\begin{tabular}{|c|c|c|c|c|c|c|}
\hline Variables & Symbol & Definitions & Mean & $\begin{array}{l}\text { Std. } \\
\text { Dev. }\end{array}$ & Min & Max \\
\hline $\begin{array}{l}\text { Unemploymen } \\
\mathrm{t}\end{array}$ & Unemp & $\begin{array}{l}\text { Unemployment, total (\% of total labor force) } \\
\text { (modeled ILO estimate) }\end{array}$ & 8.874 & 4.567 & 2.490 & 26.09 \\
\hline $\begin{array}{l}\text { Renewable } \\
\text { energy } \\
\text { production }\end{array}$ & REP & Renewables and other (quad Btu) & 0.622 & 0.437 & 0.019 & 2.331 \\
\hline $\begin{array}{l}\text { Gross domestic } \\
\text { product }\end{array}$ & GDP & GDP per capita (constant 2010 US\$) & 10.50 & 0.528 & 8.614 & 11.43 \\
\hline Investment & Investment & Gross fixed capital formation ( $\%$ of GDP) & 21.39 & 2.711 & 14.97 & 30.02 \\
\hline $\begin{array}{l}\text { Technology } \\
\text { innovation }\end{array}$ & Patent & $\begin{array}{l}\text { Patent applications, total (residents and } \\
\text { nonresidents) }\end{array}$ & 8.825 & 1.095 & 7.221 & 11.12 \\
\hline
\end{tabular}

\section{Results and Discussion}

As the objective of the study is to empirically determine the impact of renewable energy production on unemployment for a sample of selected European economies. Before executing regression analysis, it is imperative to test the stationary properties of data. Hence, panel unit root testing approaches such as LLC, IPS, and ADF unit root tests are employed in the study. Table 2 reports the outcomes of all three-panel unit root testing approaches. It is obvious that some series are stationary at the level and some of them are first difference stationary. However, none of the series is stationary at I(2). In this regard, the study adopted panel ARDL-PMG 

panel ARDL-PMG and panel NARDL-PMG along with findings of some necessary diagnostics tests.

Table 2: Panel unit root testing

\begin{tabular}{|c|c|c|c|c|c|c|c|c|c|}
\hline & LLC & & & IPS & & & ADF & & \\
\hline & $I(0)$ & I(1) & & $I(0)$ & $I(1)$ & & $I(0)$ & I(1) & \\
\hline Unemp & $-1.935^{* *}$ & & $\mathrm{I}(0)$ & $-2.752 * * *$ & & $I(0)$ & $-2.832 * * *$ & & $\mathrm{I}(0)$ \\
\hline REP & -1.035 & $-6.325 * * *$ & $\mathrm{I}(1)$ & 0.987 & $-8.356 * * *$ & $\mathrm{I}(1)$ & -1.002 & $-7.655 * * *$ & $\mathrm{I}(1)$ \\
\hline GDP & -1.032 & $-3.987 * * *$ & $\mathrm{I}(1)$ & -0.987 & $-5.988 * * *$ & I(1) & -0.782 & $-6.598 * * *$ & $\mathrm{I}(1)$ \\
\hline Investment & $-2.352^{* * *}$ & & $I(0)$ & $-3.565 * * *$ & & $I(0)$ & $-3.255^{* * *}$ & & $I(0)$ \\
\hline Patent & -0.231 & $-2.987 * * *$ & I(1) & -0.987 & $-5.988 * * *$ & $\mathrm{I}(1)$ & -0.325 & $-5.032 * * *$ & $\mathrm{I}(1)$ \\
\hline
\end{tabular}

190

Note: $* * * p<0.01 ; * * \mathrm{p}<0.05 ;$ and $* \mathrm{p}<0.00$
191

192

193

194

195

196

197

198

199

200

201

202

203

204

205

206

207

208

209

210

211

212

213

214

215

216

217

218

219

220

The long-run findings of panel ARDL-PMG reveal that renewable energy production is negatively associated with unemployment confirming that in response of 1 percent increase in renewable energy production, unemployment reduces by 1.029 percent in a sample of selected European economies. In case of control variables, GDP, investment, and patent variables exert a significant negative impact on unemployment revealing that 1 percent increase in GDP, investment and technological innovation lead to 1.086 percent, 0.789 percent and 1.534 percent reduction in unemployment in these economies in the long-run. The short-run findings of panel ARDL demonstrate that renewable energy production and patent variables have no significant impact on unemployment as the coefficient estimates of these two variables are statistically insignificant. However, GDP and investment have a significant negative impact on unemployment confirming that increase in investment and GDP results in increasing employment growth in these economies in the short-run. To confirm the findings of panel ARDL, the study performs some diagnostic tests such as Log-likelihood test, ECM, and Kao test. The coefficient estimate of Log-likelihood confirms the overall goodness of fit of the model. Furthermore, the findings of ECM and Kao test confirm the existence of long-run cointegration among variables. The coefficient estimate of ECM holds a negative sign as required for convergence, with a value 0.241 , which states that in a period of 1 year almost 24 percent convergence towards equilibrium will be achieved.

The study also scrutinizes the asymmetric impact of renewable energy production on employment growth in selected European economies. The long-run findings of panel NARDL demonstrate that positive shocks in renewable energy production have a significant negative impact on unemployment revealing that due to 1 percent increase in renewable energy production, unemployment decreases by 0.943 percent. In contrast, the negative shock is renewable energy production has a significant positive impact on unemployment showing that due to 1 percent increase in the negative component of renewable energy production, unemployment increases by 1.785 percent in the long-run.

This finding is reliable with Arvanitopoulos and Agnolucci (2020), who noted that renewable energy production contributes to stimulating employment in the United Kingdom. This study also reported that $1 \mathrm{GWh}$ increase in annual renewables creates 4.7 new jobs in the short-run period and 3.5 jobs in the long period. Azretbergenova et al. (2021) suggest that renewable energy investments generate thousands of job opportunities around the globe in the modern era. A similar finding is also found by Lehr et al. (2008) for Germany, who infers that renewable energy production has directly and indirectly increased employment. Renewable energy 
production is sometimes considered a win-win scenario for economic welfare and the environment, as they reduce $\mathrm{CO} 2$ emissions and create employment in the economy. The effect of renewable energy production on the unemployment rate is not much smaller in absolute terms in Europe. Moreno \& Lopez (2008) noted that renewable energy production offers the opportunity to reduce the emission of $\mathrm{CO} 2$ and create new employment. The finding also infers that renewable energy production increases output level by reducing unemployment in the economy. The negative effect can be explained by income and technology effects in economic theory.

As it is assumed that the renewable energy sector has increased business opportunities rapidly with also increasing the green jobs in Europe. Our finding also infers that the renewable energy sector itself has a direct impact on employment in the economy. Indirect employment includes employment in each sector of the economy in the supply chain. Destek et al. (2020) reveal that green energy also reduces the unemployment rate in Canada, Israel, France, New Zealand, and Mexico via direct and indirect transmission channels.

However, GDP, investment, and technological development significantly tend to reduce unemployment in these economies in the long-run. As it is shown that in response of 1 percent increase in GDP, investment, and technological innovation, unemployment reduces by 1.374 percent, 0.885 percent, and 2.151 percent, respectively. The short-run outcomes of panel NARDL reveal that positive shock in renewable energy production has a significant negative impact on unemployment, however, the negative shock in renewable energy production has reported no impact on unemployment. In the case of control variables, GDP and investment result in reducing unemployment but, patent variable reports no significant association between technological innovation and unemployment in the short-run. The findings of diagnostic tests also validate the empirical outcomes of NARDL. As the findings of Log-likelihood confirm the goodness of fit of the model. The findings of ECM and Kao test confirm the existence of long-run cointegrating association among variables in the long-run. The negative coefficient value of ECM demonstrates that almost 23 percent stability will be attained in the period of one year. The findings of Wald test also report that the asymmetries exist among dependent and independent variables in the long-run and short-run.

Table 3: ARDL and NARDL estimates

\begin{tabular}{|c|c|c|c|c|c|c|c|c|}
\hline & ARDL-PMG & & & & NARDL-PM & & & \\
\hline Variable & Coefficient & $\begin{array}{l}\text { Std. } \\
\text { Error }\end{array}$ & $\begin{array}{l}\text { t- } \\
\text { Statistic }\end{array}$ & Prob.* & Coefficient & $\begin{array}{l}\text { Std. } \\
\text { Error }\end{array}$ & $\begin{array}{l}\text { t- } \\
\text { Statistic }\end{array}$ & Prob.* \\
\hline \multicolumn{9}{|l|}{ Long-run } \\
\hline REP & $-1.029 * *$ & 0.494 & -2.084 & 0.038 & & & & \\
\hline REP_POS & & & & & $-0.943 * *$ & 0.470 & -2.007 & 0.046 \\
\hline REP_NEG & & & & & $-1.785^{*}$ & 1.072 & 1.665 & 0.100 \\
\hline GDP & -1.086 & 0.509 & -2.133 & 0.035 & $-1.374^{*}$ & 0.582 & -2.360 & 0.033 \\
\hline INVESTMENT & $-0.789 * * *$ & 0.087 & -9.104 & 0.000 & $-0.885^{* * *}$ & 0.086 & -10.30 & 0.000 \\
\hline PATENT & $-1.534 * * *$ & 0.520 & -2.949 & 0.004 & $-2.151 * * *$ & 0.634 & -3.391 & 0.001 \\
\hline \multicolumn{9}{|l|}{ Short-run } \\
\hline$D(R E P)$ & 0.665 & 0.999 & 0.665 & 0.507 & & & & \\
\hline D(REP_POS) & & & & & $-0.017^{*}$ & 0.009 & 1.888 & 0.078 \\
\hline $\mathrm{D}$ (REP_NEG) & & & & & -1.902 & 2.618 & -0.726 & 0.468 \\
\hline $\mathrm{D}(\mathrm{GDP})$ & -1.220 & 0.443 & $-2.753^{*}$ & 0.005 & $-2.600 * * *$ & 0.668 & -3.892 & 0.004 \\
\hline D(INVESTMENT) & $-0.161 * *$ & 0.079 & -2.033 & 0.043 & $-0.127 * *$ & 0.070 & -1.814 & 0.080 \\
\hline
\end{tabular}




\begin{tabular}{|c|c|c|c|c|c|c|c|c|}
\hline D(PATENT) & 0.492 & 1.215 & 0.405 & 0.686 & 0.241 & 1.402 & 0.172 & 0.864 \\
\hline C & $58.44 * * *$ & 14.04 & 4.161 & 0.000 & $56.51 * * *$ & 14.31 & 3.948 & 0.000 \\
\hline \multicolumn{9}{|l|}{ Diagnostics } \\
\hline Log likelihood & -166.18 & & & & -158.9 & & & \\
\hline $\operatorname{ECM}(-1)$ & $-0.241 * * *$ & 0.058 & -4.168 & 0.000 & $-0.231 * * *$ & 0.059 & -3.940 & 0.000 \\
\hline $\begin{array}{l}\text { Kao- } \\
\text { cointegration }\end{array}$ & $-3.255^{* * *}$ & & & & $-3.589 * * *$ & & & \\
\hline Wald-LR & & & & & $4.658 * * *$ & & & \\
\hline Wald-SR & & & & & $3.878 * * *$ & & & \\
\hline
\end{tabular}

Note: $* * * p<0.01 ; * * p<0.05 ;$ and $* \mathrm{p}<0.0$

Table 4 portrays the results of quantile regression estimates. Although we have presented the complete 250 results of all our variables; however, to save space, we only discuss the results of our primary variable. In total,

251 we have included 11 quantiles. The estimates of REP are negative significant in symmetric quantile regression.

252 In addition, the asymmetric effects of renewable energy production on unemployment growth are robust in the

253 different quantile regression.

255 Table 4: Panel quantile regression

\begin{tabular}{|c|c|c|c|c|c|c|c|c|c|c|c|}
\hline & 0.05 & 0.10 & 0.20 & 0.30 & 0.40 & 0.50 & 0.60 & 0.70 & 0.80 & 0.90 & 0.95 \\
\hline \multicolumn{12}{|c|}{ Models without asymmetry } \\
\hline REP & $-0.969 * * *$ & $-1.376 * * *$ & $-1.971 * * *$ & $-2.384 * * *$ & $-3.187 * * *$ & $-3.781 * * *$ & $-4.589 * * *$ & $-5.565 * * *$ & $-6.394 * * *$ & $-6.017 * * *$ & $-7.763 * * *$ \\
\hline GDP & 0.041 & 0.016 & -0.172 & $-0.311 * * *$ & -0.231 & 0.021 & 0.365 & 0.489 & $0.951^{* *}$ & $3.297 * * *$ & $6.277^{* * *}$ \\
\hline INVESTMENT & 0.023 & 0.074 & 0.108 & $0.172 * *$ & $0.193^{* *}$ & 0.112 & -0.004 & -0.086 & $-0.232^{*}$ & $-0.322 *$ & $-1.016^{* *}$ \\
\hline PATENT & $0.401^{* *}$ & $0.411^{* *}$ & $0.693 * * *$ & $0.817^{* * *}$ & $0.828 * * *$ & $0.848^{* * *}$ & $0.895^{* * *}$ & $1.144^{* * *}$ & $1.154^{* * *}$ & -1.063 & $-2.187^{*}$ \\
\hline \multicolumn{12}{|c|}{ Models with asymmetry } \\
\hline REP_POS & $-1.399 * * *$ & $-1.909 * * *$ & $-2.008 * * *$ & $-2.795 * * *$ & $-3.408 * * *$ & $-3.581 * * *$ & $-4.119 * * *$ & $-4.515 * * *$ & 0.755 & -5.069 & 5.571 \\
\hline REP_NEG & -0.905 & $-2.068 * * *$ & $-2.414 * * *$ & $-2.997 * * *$ & $-3.845 * * *$ & $-3.168 * *$ & $-3.918 * * *$ & $-3.405^{* *}$ & 4.421 & -7.697 & $3.061 *$ \\
\hline GDP & -0.479 & $-0.900 * * *$ & $-1.101^{* * *}$ & $-1.257 * * *$ & $-1.188^{* * *}$ & -0.497 & -0.240 & 0.021 & 0.187 & 2.049 & 3.052 \\
\hline INVESTMENT & 0.131 & $0.246^{* * *}$ & $0.285^{* * *}$ & $0.331 * * *$ & $0.290 * * *$ & 0.195 & 0.140 & 0.055 & 0.102 & -0.231 & -0.132 \\
\hline PATENT & $0.759 * * *$ & $1.054^{* * *}$ & $1.263^{* * *}$ & $1.440 * * *$ & $1.557^{* * *}$ & $1.097 * * *$ & $1.043^{* * *}$ & $1.085^{* * *}$ & $0.879 *$ & -0.060 & -0.930 \\
\hline
\end{tabular}

$256 \quad$ Note: $* * * \mathrm{p}<0.01 ; * * \mathrm{p}<0.05 ;$ and $* \mathrm{p}<0.00$

257

258

259

260

261

262

263

264

265

266

267

268

\section{Conclusion and implications}

Due to environmental degradation and energy supply sanctuary issues, the energy sector has transformed towards renewable energy production. The increasing trend of investments in the field of renewable energy creates substantial support to the development and economic growth by increasing production levels and by generating more employment. The current study examines the effect of renewable energy production on the employment growth in the case of European countries namely Austria, Finland, France, Germany, Italy, Norway, Poland, Spain, and Sweden for period 1991 to 2019. For this purpose, the study employed panel ARDL and panel NARDL regression techniques. GDP, investment, and technological innovation are also incorporated as control variables in the study. The long-run findings of panel ARDL report that due to an increase in 
renewable energy production, employment growth increases significantly. However, short-run findings of ARDL do not report any significant impact of renewable energy production on employment growth.

The long-run outcomes of NARDL demonstrate that positive shock in renewable energy production leads to employment growth in these economies however, negative shock in renewable energy production results in increased unemployment in the long-run. The short-run findings of NARDL also report employment growth due to positive changes in renewable energy production. The finding does not report any significant impact of negative shock of renewable energy production on employment growth in the short-run. In case of control variables, the findings of panel ARDL and panel NARDL models reveal that any increase in GDP, investment and Patent variables result in a reduction of unemployment in these economies in the long-run. However, in the short, the findings of panel ARDL and panel NARDL models reveal that GDP and investment result in increasing employment growth but patent has no significant impact on employment growth.

In short, renewable energy production and other variables exert a significant positive impact on employment growth in the sample of selected European economies. On the basis of these findings, the study proposed several policy recommendations. Firstly, capital investment in renewable energy sector-related technologies should be increased. Secondly, the joint projects, support projects, statistical transfers, and collaborations should be strengthened among these selected economies on renewable energy production. Thirdly, the utilization of fossil fuels should be minimized and the appropriate domains for the renewable energy sector amenities should be determined. Lastly, the governments should adopt such strategies that fulfill the necessities of the energy sector, containing the training of future workforces that improves regional competitiveness and generates positive influences on the labour market. In addition, the European governments should also provide some tax benefits, price guarantees, subsidies, and easy financing opportunities inspiring the green energy sector to increase its employment level.

\section{Declarations}

Ethical Approval-Not applicable.

Consent to Participate-Not applicable.

Consent to Publish-All authors have read and approved the manuscript to publish with this journal.

Authors Contributions-Conceptualization, writing, referencing and final format: Sameen Naqvi. Data analysis and result: Sameen Naqvi and Jinchao Wang. Supervision, proofreading and review: Jinchao Wang and Rizwan Ali.

Funding-There is no finding source

Competing Interests-The authors declare that they have no competing interests.

Availability of data and materials- Data is available from the corresponding author upon request.

\section{References}

Apergis, N., \& Salim, R. (2015). Renewable energy consumption and unemployment: evidence from a sample of 80 countries and nonlinear estimates. Applied Economics, 47(52), 5614-5633.

Arvanitopoulos, T., \& Agnolucci, P. (2020). The long-term effect of renewable electricity on employment in the United Kingdom. Renewable and Sustainable Energy Reviews, 134, 110322.

Azretbergenova, G., Syzdykov, B., Niyazov, T., Gulzhan, T., \& Yskak, N. (2021). The relationship between renewable energy production and employment in european union countries: Panel data analysis. Int. J. Energy Econ. Policy, 11, 20-26. 
Blanco, M. I., \& Rodrigues, G. (2009). Direct employment in the wind energy sector: An EU study. Energy policy, 37(8), 2847-2857.

Böhringer, C., Keller, A., \& Van der Werf, E. (2013). Are green hopes too rosy? Employment and welfare impacts of renewable energy promotion. Energy Economics, 36, 277-285.

Breitschopf, B., Held, A., \& Resch, G. (2016). A concept to assess the costs and benefits of renewable energy use and distributional effects among actors: The example of Germany. Energy \& Environment, 27(1), 55-81.

Çelik, O. (2021). Assessment of the relationship between renewable energy and employment of the United States of America: Empirical evidence from spectral Granger causality. Environmental Science and Pollution Research, 1-8.

Destek, M. A., Ozsoy, F. N., \& Ozpolat, A. (2020). Investigation on the job creation effect of green energy in OECD countries. In Econometrics of green energy handbook (pp. 131-149). Springer, Cham.

Hillebrand, B., Buttermann, H. G., Behringer, J. M., \& Bleuel, M. (2006). The expansion of renewable energies and employment effects in Germany. Energy Policy, 34(18), 3484-3494.

Koenker, R. (2004). Quantile regression for longitudinal data. Journal of Multivariate Analysis, 91(1), 74-89.

Koenker, R., \& Bassett Jr, G. (1978). Regression quantiles. Econometrica: journal of the Econometric Society, 33-50.

Lehr, U., Nitsch, J., Kratzat, M., Lutz, C., \& Edler, D. (2008). Renewable energy and employment in Germany. Energy policy, 36(1), 108-117.

Mbarek, M. B., Abdelkafi, I., \& Feki, R. (2018). Nonlinear causality between renewable energy, economic growth, and unemployment: evidence from Tunisia. Journal of the Knowledge Economy, 9(2), 694702.

Meyer, I., \& Sommer, M. W. (2014). Employment Effects of Renewable Energy Supply-A Meta Analysis. Policy Paper, 12.

Moreno, B., \& Lopez, A. J. (2008). The effect of renewable energy on employment. The case of Asturias (Spain). Renewable and Sustainable Energy Reviews, 12(3), 732-751.

Pachauri, R. K., Meyer, L. A., Plattner, G. K., \& Stocker, T. (2014). Synthesis report. Contribution of working groups I, II and III to the fifth assessment report of the Intergovernmental Panel on Climate Change. Intergovernmental Panel on Climate Change: Geneva, Switzerland.

Pesaran, M. H., Shin, Y., \& Smith, R. J. (2001). Bounds testing approaches to the analysis of level relationships. Journal of applied econometrics, 16(3), 289-326.

Rivers, N. (2013). Renewable energy and unemployment: A general equilibrium analysis. Resource and Energy Economics, 35(4), 467-485.

Shin, Y., Yu, B., \& Greenwood-Nimmo, M. (2014). Modelling asymmetric cointegration and dynamic multipliers in a nonlinear ARDL framework. In Festschrift in honor of Peter Schmidt (pp. 281-314). Springer, New York, NY.

Yi, H. (2013). Clean energy policies and green jobs: An evaluation of green jobs in US metropolitan areas. Energy policy, 56, 644-652. 